\title{
Overview of NASA Langley's Systems Analysis Capabilities
}

\author{
Stephen Cavanaugh, Ajay Kumar, Laura Brewer, Bill Kimmel, John \\ Korte, Tom Moul \\ NASA Langley Research Center, Hampton, Virginia 23666
}

\section{Introduction}

The Systems Analysis and Concepts Directorate (SACD) has been in the systems analysis business line supporting National Aeronautics and Space Administration (NASA) aeronautics, exploration, space operations and science since the 1960's. Our current organization structure is shown in Figure 1. SACD mission can be summed up in the following statements:

1. We conduct advanced concepts for Agency decision makers and programs.

2. We provide aerospace systems analysis products such as mission architectures, advanced system concepts, system and technology trades, life cycle cost and risk analysis, system integration and pre-decisional sensitive information.

3. Our work enables informed technical, programmatic and budgetary decisions.

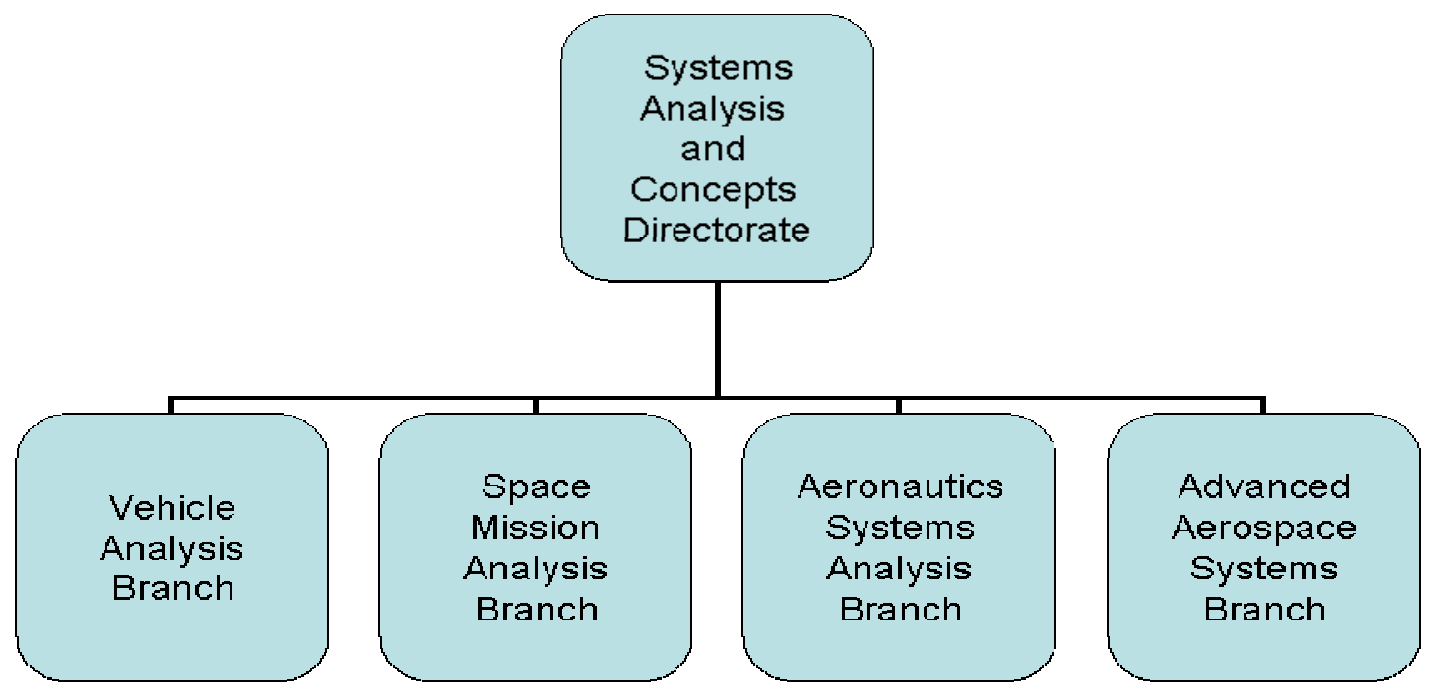

Figure 1 - SACDs Orginization ${ }^{1}$

SACD has a complement of 114 government employees and approximately 50 on-site contractors which is equally split between supporting aeronautics and exploration. SACD strives for technical excellence and creditability of the systems analysis products delivered to its customers. The Directorate office is continuously building market intelligence and working with other NASA centers and external partners to expand our business base. The Branches strive for technical excellence and credibility of our systems analysis products by seeking out existing and new partnerships that are critical for successful systems analysis. The Directorates long term goal is to grow the amount of science systems analysis business base.

\section{$\underline{\text { SACD Customers, Products and Services }}$}

SACD's customers consist of NASA, Industry, Academia, Department of Defense and other government agencies. The types of systems analysis and the resulting products and services are shown in Figure 2. 


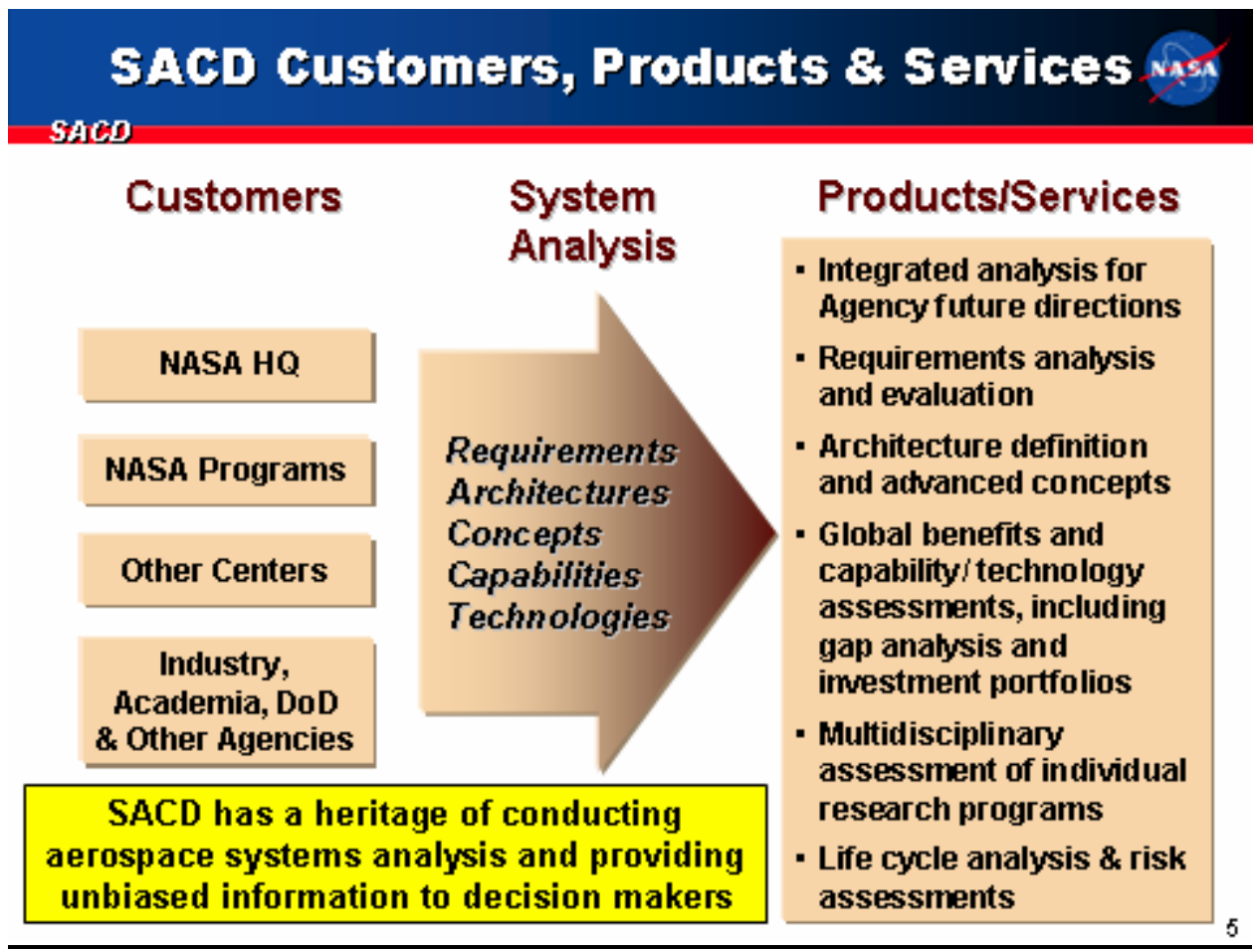

Figure 2 - SACDs Customers, Products \& Services

\section{Implementation of the Exploration Vision and Aeronautics Mission}

NASA's new Exploration Vision outlines goals and objectives for human and robotic exploration of the Moon, Mars and beyond. A primary goal of this Vision is to implement a program meeting these objectives in a sustainable and affordable manner. While implementing the exploration program, the Agency will continue to conduct activities sponsored by its other mission directorates. To establish a sustainable and affordable exploration program while optimizing resources across other Agency activities, decision makers need systems analysis to provide them with timely and effectual program-related information.

NASA is also in the process of reshaping the Aeronautics program under the following three guiding principles.

1. We will dedicate ourselves to the mastery and intellectual stewardship of the core competencies of Aeronautics for the Nation in all flight regimes.

2. We will focus our research in areas that are appropriate to NASA's unique capabilities.

3. We will directly address the R\&D needs of the Next Generation Air Transportation System (NGATS) in partnership with the member agencies of the Joint Planning and Development Office (JPDO).

Implementation of these principles will be to conduct long-term, focused, cutting-edge research. All research will be integrated using a holistic approach which is needed to bring about system-level revolutionary capabilities. This long-term research will have milestones to enable continual assessment of research portfolio and short-term "products" while sticking to long-term revolutionary goals. SACD systems analysis can assist Aeronautics decision makers in making informed decisions regarding its longterm goals. A four-step planning process is currently under way to accomplish these guiding principles.

1. Assess the long-term research needs and goals in each Program and develop technical roadmaps to accomplish those goals. 
2. Solicit information on key areas of interest from the external community and determine opportunities for collaboration through an RFI.

3. Define research proposals at the field centers.

4. Issue NASA Research Announcements to solicit proposals for foundational research.

Implementing the Vision for Space
Exploration coal and Objectives

- Fundamental goal of this vision is to advance U.S. scientific, security \& economic interests through a robust space exploration program.

- In support of this goal, the United States will:

- Implement a sustained and affordable human and robotic program to explore the solar system \& beyond

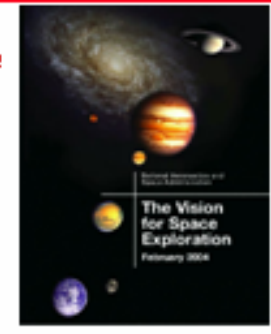

- Extend human presence across the solar system, starting with a human return to the Moon by the year 2020, in preparation for human exploration of Mars and other destinations

- Develop the innovative technologies, knowledge, and infrastructures both to explore and to support decisions about the destinations for human exploration

- Promote international and commercial participation in exploration to further U.S. scientific, security, \& economic interests
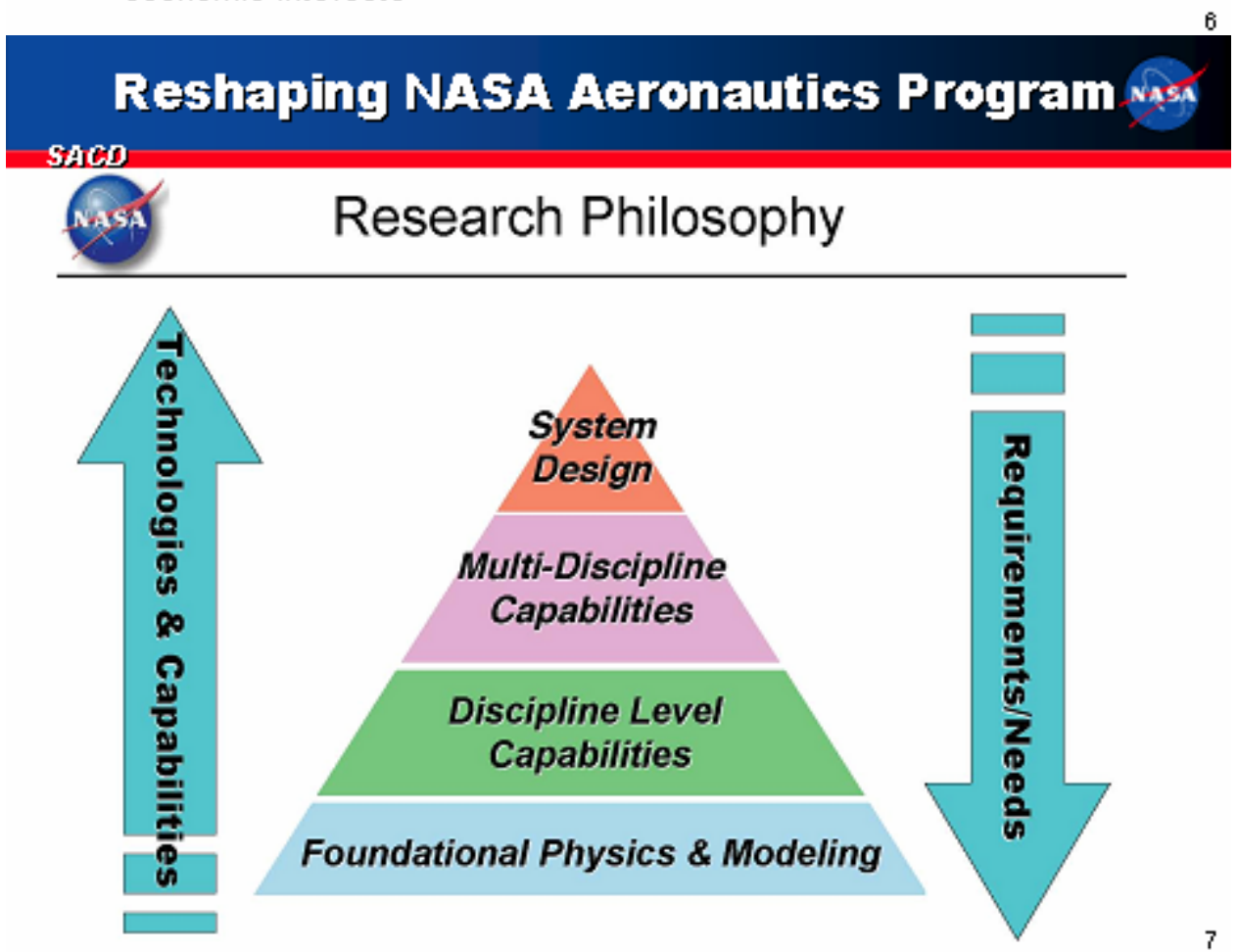

Figure 3 - Exploration Vision \& Aeronautics Program 
This information need, as shown in Figure 3, affords a unique opportunity to utilize established systems analysis processes and reinvigorate the Agency's systems engineering competency. Before we proceed with a discussion of SACD capabilities, it is appropriate to define some terminology to set the stage.

\section{Systems Engineering Solutions}

Systems engineering is a robust approach to the design, creation, and operation of systems. In simple terms, the approach consists of identification and quantification of system goals and requirements, definition and assessment of system design concept options, performance of design trades, selection and implementation of the best design, verification that the design is properly built and integrated, and postimplementation assessment of how well the system meets (or met) the goals and requirements.

Systems analysis, a component of systems engineering, is defined as the integration of advanced concept/architecture generation coupled with the application of various technologies where benefits and sensitivities are assessed using figures of merit (FOMs). These FOMs are metrics that span performance, risk, cost and schedule. Systems analysis is dominant in the formulation phase of a program, while system design is dominant during the implementation phase as depicted in figure 4. During the formulation phase, systems analysis is used to identify the best architecture to build and operate. Systems analysis is used to generate information for Agency decision makers by balancing requirements, functional allocation, and designs with performance, cost, and risk.

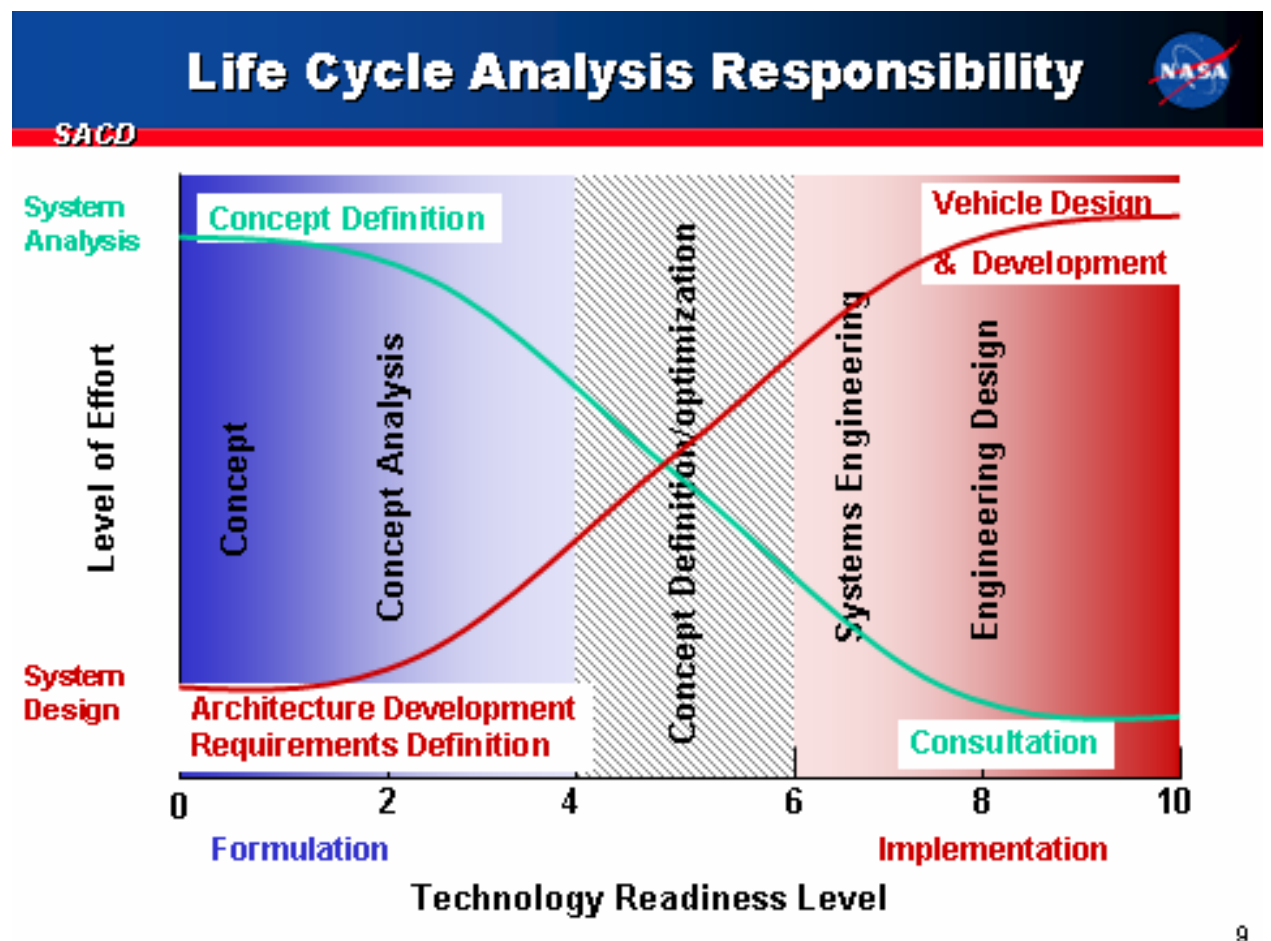

Figure 4 - Life Cycle Analysis Responsibility

\section{Required Systems Engineering Capabilities}

The following are SACD Level 1 system engineering capabilities needed by the Agency to successfully achieve the Exploration Vision:

- Systems Management

- Systems Analysis / Modeling and Simulation 
- $\quad$ Research \& Technology Development Management

- Requirements Definition \& Functional Analysis

\section{Systems Engineering Roles and Capabilities}

SACD traditional role is to conduct systems analyses, including analysis of alternatives, as the technical conscience for large programs such as Apollo, Space Shuttle, and Space Station. The main design, development, and operation activities are traditionally performed at Johnson Space Center, Marshall Space Flight Center, and Kennedy Space Center.

1. For the Apollo program, SACD developed the selected approach of the Lunar Orbit Rendezvous that controlled weight, provided manageable system module development, provided the greatest payload growth potential, and used the existing technology or technology under development.

2. For the Space Shuttle Orbiter, the double-delta wing configuration was selected based on ease of reentry and landing control and better aerothermodynamics heating. For the Space Station program, SACD developed a number of configuration alternatives for the program office as requirements changed and is assessing impacts of Space Shuttle termination.

3. SACD is currently applying systems analysis capabilities to the Exploration Vision to analyze system concepts and architectures, prioritize mission-enabling technologies, and perform technology assessments that will guide NASA's strategic investment portfolios across all NASA missions.

Shown in figure 5 are the steps that SACD takes for its support of NASA's programs. Outputs of this process are requirements validation, analysis of alternatives for the architecture, trades of technology/cost/risk, and assessment of technology portfolios for investment decisions.

SACD is considered an "honest broker" since Langley Research Center is not a developer of major systems. This role allows SACD to provide an unbiased assessment of all system alternatives. In addition, being close to NASA Headquarters, the SACD team can be embedded within Headquarters to provide quick responses to architecture and/or technology questions. With SACD system analysis breadth in launch systems, exploration systems, aeronautics, and supporting infrastructure and operations, we can ensure the best system of systems approach. SACD continues to be the principle Agency provider of aerospace systems analysis and decision support of these Agency systems engineering efforts.

SACD systems engineering capabilities, which will be written about in detail in a series of papers for this conference, include the following:

Mission and Trade Study Analysis: Mission analysis describes all study and design efforts that relate to a determination of what the project's mission should be and how it should be carried out. Architectures consist of the integrated set of functional building blocks that describe the method and style by which a set of activities are carried out to accomplish specified goals, and subsequently return science and crews to Earth. The functional building blocks take the form of advanced systems concepts that are built upon technologies that are often referred to as enabling capabilities. Alternate mission architectures and system concepts will be modeled to determine the effectiveness of the various system concepts in implementing the preferred system architectures and providing the desired functional capabilities. The key enabling technologies required will be identified as a product of the trade studies, including desired performance levels. Analyses conducted will address performance, cost, risk, and safety considerations. Trade studies are then used to quantify system effectiveness and cost, and the pitfalls to avoid. These analyses are support by modeling and simulation. Modeling and simulation is a discipline for developing a level of understanding of the interaction of the parts of a system, and of the system as a whole. The level of understanding that is developed via this discipline can be used to facilitate tactical decisions over a wide range of scenarios. 


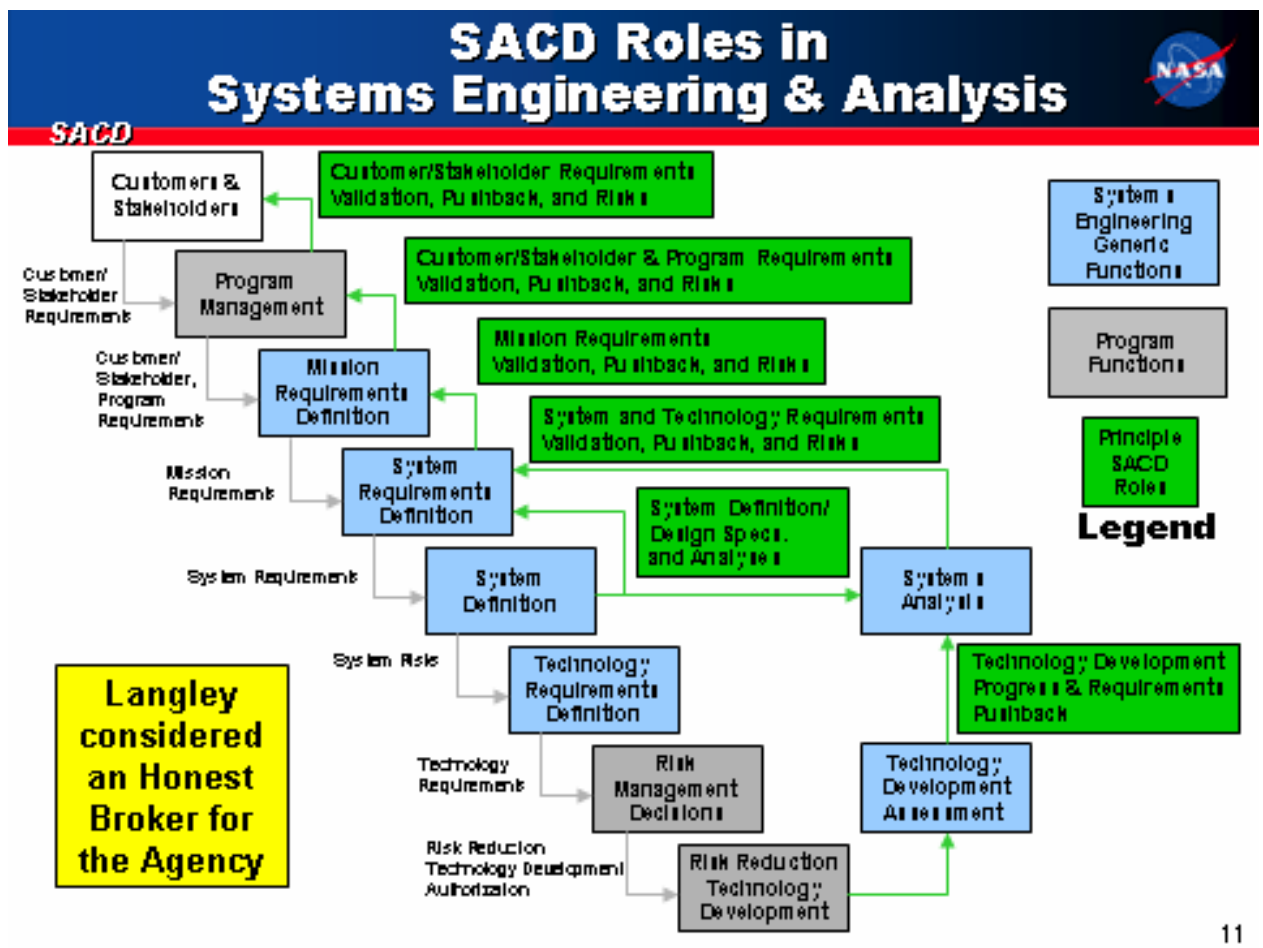

Figure 5 - SACDs main roles in Systems Engineering and Analysis

Life Cycle Analysis and Uncertainty Analysis: Life Cycle Analysis (LCA) is the evaluation of the impacts that design decisions have on a system and provides a framework for identifying and evaluating design benefits and burdens associated with the life cycles of space transportation systems from a "cradleto-grave" approach. Sometimes called "life cycle assessment", "life cycle approach", or "cradle to grave analysis", it represents a rapidly emerging family of tools and techniques designed to be a decision support methodology and aid in the development of sustainable systems. The implementation of a Life Cycle Analysis can vary and may take many forms; from global system-level uncertainty-centered analysis to the assessment of individualized discriminatory metrics.

Risk Analysis: Risk analysis is the process of quantifying both the likelihood of occurrence and the likelihood of consequence of a potential future event. Uncertainty quantification, propagation, decomposition, and management techniques, robust design methods, risk analysis, and logic-evolved decision analysis methodologies are all currently used within SACD. These disciplines are used under the name of decision support methods and tools.

Technology Assessment/Portfolio Analysis: Systems analysis develops and documents candidate architectures, associated system concepts, enabling capabilities and investment strategies to achieve NASA's strategic objectives. The technology assessment process connects the architectures to the investment strategies. In order to successfully implement a technology assessment, there is a need to collect, manipulate, analyze, document, and disseminate technology-related information. Information must be collected and organized on the wide variety of potentially applicable technologies, including: previous research results, key technical parameters and characteristics, technology readiness levels, relationships to other technologies, costs, and potential barriers and risks. This information must be manipulated to facilitate planning and documentation. An assessment is included of the programmatic and technical risks associated with each technology task as well as potential risk mitigation plans. Risks are assessed and tracked in terms of likelihood of the risk occurring and consequences of the risk if it does occur. The risk assessments take into account cost, schedule, and technical risk dimensions. Assessment data must be simplified for presentation to decision makers. 
SACD recent experience in systems analysis type studies is shown below and is presented in detail in separate corresponding papers for this conference:

Exploration Systems Architecture Study (ESAS): In May of 2005, NASA initiated the Exploration Systems Architecture Study (ESAS). The purpose of the study was to:

1) Assess the top-level Crew Exploration Vehicle (CEV) requirements and plans that enable the CEV to provide crew transport to the International Space Station (ISS);

2) Define top-level requirements and configurations for crew and cargo launch systems to support the lunar and Mars exploration programs;

3) Develop a reference exploration architecture concept to support sustained human and robotic lunar exploration operations; and

4) Identify key technologies required to enable and significantly enhance these reference exploration systems and a reprioritization of near-term and far-term technology investments.

SACD had significant roles in supporting the ESAS study team. SACD performed the liaison risk assessment functions between the ESAS team and an agency wide team charged with using the Shuttle to complete the ISS by 2010. SACD performed numerous Lunar Surface Access Module (LSAM) trades to define top level element requirements and establish architecture propellant needs. The technology assessment process was developed and implemented by SACD as the ESAS architecture was refined.

Hyper-X Program: SACD played major roles in a recent hypersonic testing program that broke world records in the Mach 7 and 10 speed regimes. SACD engineers were part of the integrated team, providing critical support, analysis, and leadership to the Hyper-X Program throughout the program's entire life and were key to its ultimate success. Engineer's in SACD's Vehicle Analysis Branch (VAB) were involved in all stages and aspects of the program, from conceptual design prior to contract award, through preliminary design and hardware development, pre-flight analysis, day-of-flight support, and post-flight analysis for all three flight tests. Working closely with other engineers at Langley and Dryden, as well as industry partners, roughly 20 members of SACD were involved in the evolution of the Hyper-X program in nearly all disciplines, including lead roles in several areas. Engineers from VAB led the aerodynamic database development, the propulsion database development, and the stage separation analysis and risk assessment effort. Others played major roles in structures, aerothermal, GN\&C, trajectory analysis and flight simulation, as well as providing CFD support for aero, propulsion, and aerothermal analysis.

Utilizing Traveler Demand Modeling to Predict Future Commercial Flight Schedules: The flights in the airspace system occur as a response to the demand of passenger travel requirements. Currently, the airspace system is plagued with delays at many of its major hub airports, especially in bad weather conditions. SACD is currently leading a study that incorporates the Transportation Systems Analysis Model (TSAM) to predict the future demand for airline travel. A major strength of the TSAM analysis is that scenario planning can be conducted to quantify capacity requirements at individual airports, based upon different future scenarios. Although fare yields combined with the demographics and national economic prosperity tend to dominate normal air traffic demand, other factors also play roles in the traveler's mode choice. For instance, if the check-in, security clearance, and wait time at each large hub airport were increased a total of 30 minutes, and at medium and small hubs by 15 minutes, TSAM indicates that an additional $4.3 \%$ of business travelers and $3.1 \%$ of non-business travelers in 2014 would drive rather than fly commercial air. To add perspective, this is about 33 million enplanements which is approximately the growth expected to occur between 2013 and 2014. Delays and/or stretching out fight schedules have a similar effect and can be quantified in terms of the effect on the traveler's mode choices.

Additional key SACD contributions in systems engineering and analysis are shown in figure 6 below. 


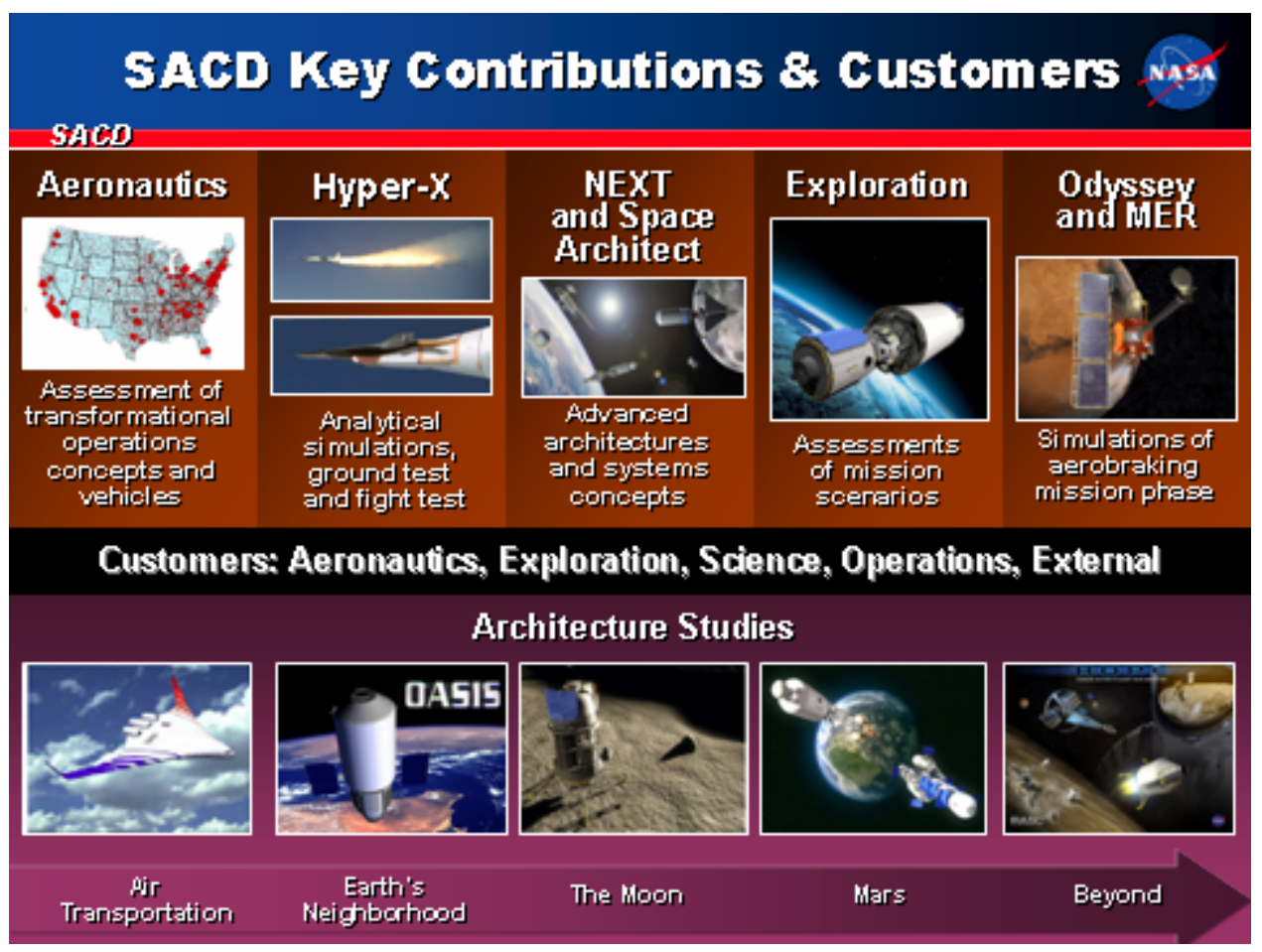

Figure 6 - SACDs Key Contributions and Customers

Revolutionary Aerospace Systems Concepts (RASC): This recent past Agency program identified and analyzed alternative and revolutionary aerospace system concepts derived from NASA goals over the complete mission design space while also identifying requirements for critical technologies enabling these paradigm-shifting concepts. RASC architecture studies led and integrated by SACD were used in formulating the Agency's Exploration Vision.

Aeronautics Systems Analysis (ASA): In support of this recent past activity, SACD performed top-down systems analysis to identify technology investment areas for R\&T planning; and performed systems analysis of existing, funded programs to assess enabling/enhancing technologies.

Contributions to Mars Planetary Exploration: SACD has supported Mars exploration missions from concept definition through flight operations in the past. Langley areas of expertise include: atmospheric flight trajectory simulation; aerodynamics; aeroheating; flight controls; configuration development; and systems analysis.

SACDs relevance to the NASA missions is shown in figure 7.

\section{Summary}

Process, tools and personnel exist within SACD to perform systems analysis studies for the Agency decision makers either in direct support to a program and/or in an honest broker fashion. SACD has the expertise to lead and participate in advanced concept studies, architecture definition and project concept formulation for:

1. End-to-End Flight Simulation

2. Systems Engineering: Architecture to requirements and functional analysis

3. Atmospheric Flight Mechanics/Aerodynamics/Aeroheating

4. Stage Separation

5. Aeroelasticity \& Structural Analysis 
6. Entry-Decent-Landing: Parachutes, precision landing \& attenuation

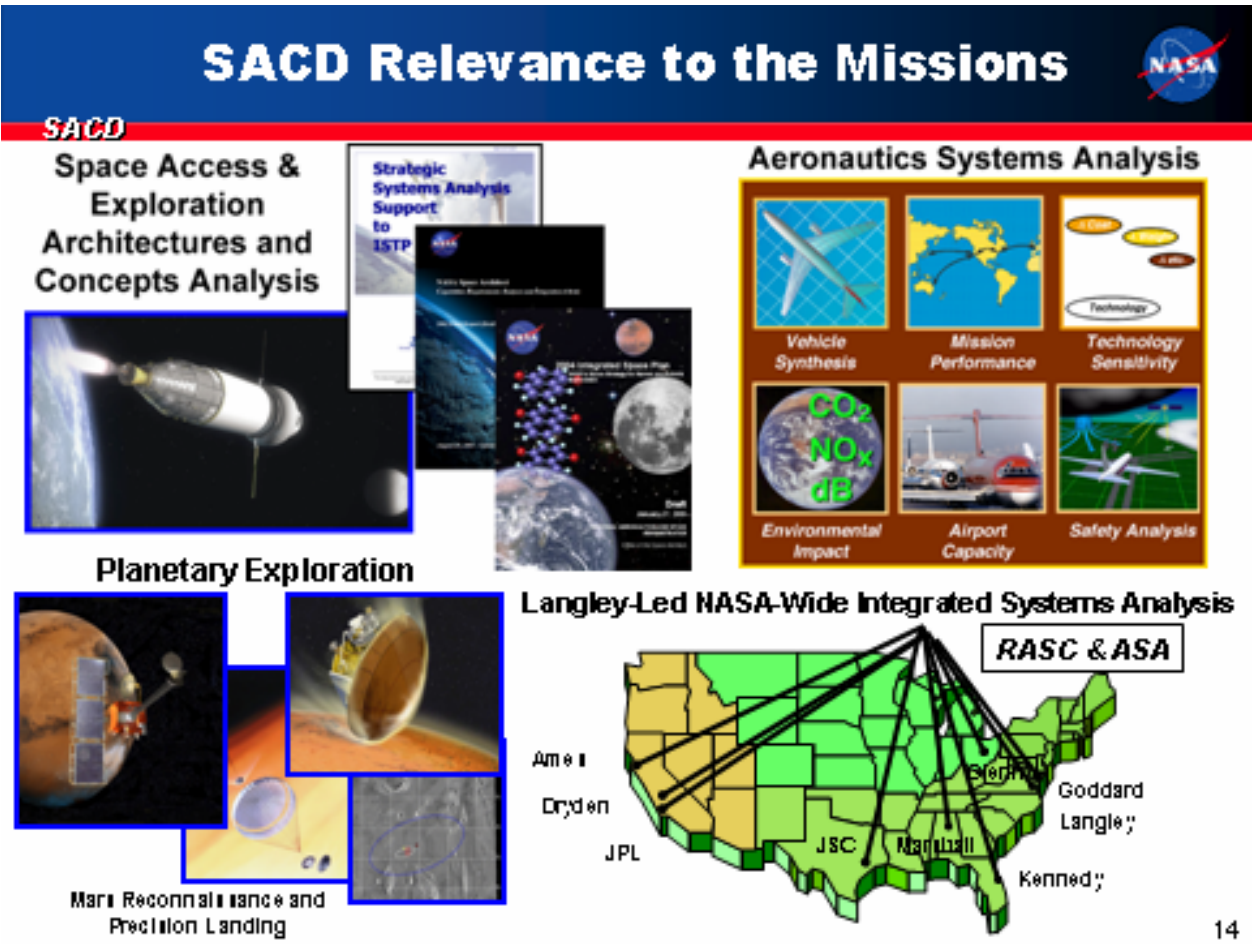

Figure 7 - SACDs Relevance to the Missions 